\title{
Reduced FRG1 expression promotes prostate cancer progression and affects prostate cancer cell migration and invasion
}

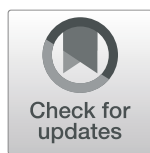

Ankit Tiwari ${ }^{1}$, Bratati Mukherjee ${ }^{1}$, Md. Khurshidul Hassan', Niharika Pattanaik², Archita Mohanty Jaiswal ${ }^{2}$ and Manjusha Dixit ${ }^{1 *}$

\begin{abstract}
Background: Prostate cancer is the most common form of cancer in males and accounts for high cancer related deaths. Therapeutic advancement in prostate cancer has not been able to reduce the mortality burden of prostate cancer, which warrants further research. FRG1 which affects angiogenesis and cell migration in Xenopus, can be a potential player in tumorigenesis. In this study, we investigated the role of FRG1 in prostate cancer progression.

Methods: Immunohistochemistry was performed to determine FRG1 expression in patient samples. FRG1 expression perturbation was done to investigate the effect of FRG1 on cell proliferation, migration and invasion, in DU145, PC3 and LNCaP cells. To understand the mechanism, we checked expression of various cytokines and MMPs by q-RT PCR, signaling molecules by western blot, in FRG1 perturbation sets. Results were validated by use of pharmacological inhibitor and activator and, western blot.

Results: In prostate cancer tissue, FRG1 levels were significantly reduced, compared to the uninvolved counterpart. FRG1 expression showed variable effect on PC3 and DU145 cell proliferation. FRG1 levels consistently affected cell migration and invasion, in both DU145 and PC3 cells. Ectopic expression of FRG1 led to significant reduction in cell migration and invasion in both DU145 and PC3 cells, reverse trends were observed with FRG1 knockdown. In androgen receptor positive cell line LNCaP, FRG1 doesn't affect any of the cell properties. FRG1 knockdown led to significantly enhanced expression of GM-CSF, MMP1, PDGFA and CXCL1, in PC3 cells and, in DU145, it led to higher expression of GM-CSF, MMP1 and PLGF. Interestingly, FRG1 knockdown in both the cell lines led to activation of p38 MAPK. Pharmacological activation of p38 MAPK led to increase in the expression of GM-CSF and PLGF in DU145 whereas in PC3 it led to enhanced expression of GM-CSF, MMP1 and CXCL1. On the other hand, inhibition of p38 MAPK led to reduction in the expression of above mentioned cytokines.

Conclusion: FRG1 expression is reduced in prostate adenocarcinoma tissue. FRG1 expression affects migration and invasion in AR negative prostate cancer cells through known MMPs and cytokines, which may be mediated primarily via p38 MAPK activation.
\end{abstract}

Keywords: FRG1, Prostate cancer, Immunohistochemistry, Cell migration, Cell invasion, p38 MAPK, GM-CSF, MMP1, PLGF, CXCL1

\footnotetext{
* Correspondence: manjusha@niser.ac.in

${ }^{1}$ School of Biological Sciences, National Institute of Science Education and

Research Bhubaneswar, HBNI, PO: Bhimpur-Padanpur, Via: Jatni, Odisha

752050, India

Full list of author information is available at the end of the article
}

(c) The Author(s). 2019 Open Access This article is distributed under the terms of the Creative Commons Attribution 4.0 International License (http://creativecommons.org/licenses/by/4.0/), which permits unrestricted use, distribution, and reproduction in any medium, provided you give appropriate credit to the original author(s) and the source, provide a link to the Creative Commons license, and indicate if changes were made. The Creative Commons Public Domain Dedication waiver (http://creativecommons.org/publicdomain/zero/1.0/) applies to the data made available in this article, unless otherwise stated. 


\section{Background}

Prostate cancer is the most common form of cancer in men, and is the second and third most common cause of cancer-related death of men, in the US and Europe, respectively $[1,2]$. It is a heterogeneous disease in early stages, which requires rigorous stratification, so that the progression to the advanced stage could be predicted more accurately [3]. Advances are being made in the treatment and etiological understanding of prostate cancer. Still the abundance of resistant tumor types and the burden of prostate cancer related death, poses a question regarding better etiological understanding of the disease [4]. Consequently, the search for novel regulators and molecular mechanism, associated with prostate cancer, is of the utmost significance.

To enhance the understanding about additional players in prostate cancer, FRG1 can be a good candidate. FRG1 is a candidate gene for Facioscapulohumeral muscular dystrophy (FSHD) [5] but it has also been shown to affect vasculature [6]. Functional domain analysis of FRG1 revealed that it consists of a fascin like domain. Fascin is an actin bundling protein which is known to be involved in tumor progression [7]. FRG1 is also essential for differentiation of amleoblasts, odontoblasts and matrix formation, associating it with BMP4 which is well known tumorigenesis regulator [8]. Above mentioned studies provide indications of possible involvement of FRG1 in tumorigenesis. Oncomine datamining, in our previous work, showed the reduced expression of FRG1 in more studies, which includes prostate cancer. Additionally, Kaplan Meier plotter analysis revealed that low FRG1 expression was associated with poor prognosis in overall survival of patients, in lung cancer and in gastric cancer [9]. Somatic mutation analysis shows $0.24 \%$ frequency in COSMIC [10], $1.8 \%$ in cBioPortal [11] [12], and 5.37\% in TCGA databases, respectively. Couple of recent studies have reported mutations in FRG1 gene in cancer patients [13] [14].

On the whole, all above mentioned facts strongly support towards the possible role of FRG1 in prostate cancer, which is completely unexplored. Therefore, we intend to understand the etiological function of FRG1 in prostate cancer. In this study we used three different prostate cancer lines to establish role of FRG1 with respect to androgen receptor status and varying invasiveness. DU145 and PC3 cell lines are androgen receptor (AR) negative and are more invasive, on the contrary, LNCaP is AR positive and less invasive. We perturbed the expression levels of FRG1 and checked the effect on various cell properties. We used DU145 and PC3 cell line, in which we found positive effect of FRG1 expression level on cell properties, for mechanistic studies.

\section{Methods}

\section{Patients and tissue microarray}

Study included archival formalin-fixed, paraffin-embedded (FFPE) blocks from patients with acinar adenocarcinoma of prostate $(N=20)$, who underwent needle core biopsy of prostate from 2014 to 2015. FFPE blocks were obtained from tissue archives of SRL Bhubaneswar, at Kalinga Hospital Pvt. Limited Bhubaneswar, India. Patient who had undergone treatment prior to biopsy were excluded from our study. All the cases were reviewed by two independent pathologists N.P. and A.M.J. The clinicopathological features for cases were identified prior to selection of cases. The study was approved (BioEthics \# MD-1) by institutional ethics committee, National Institute of Science Education and Research (NISER), Bhubaneswar, India. Further, to increase sample size, tissue array consisting of 90 cores of prostate adenocarcinoma along with paired uninvolved adjacent tissue was procured from Biomax (USA).

\section{Immunohistochemistry}

The tumor tissue was fixed in $10 \%$ buffered formalin, embedded in paraffin, and serially sectioned at $4 \mu \mathrm{m}$ thickness. Sections were deparaffinized and rehydrated. Heat induced epitope retrieval was done using microwave in Envision target retrieval solution High $\mathrm{pH}$ (Dako, USA). Immunohistochemistry procedure was followed as mentioned in Dako Envision Plus kit manual (Dako). FRG1 antibody was diluted at 1:100 for immunohistochemistry (IHC). HeLa cell block was stained, as control for FRG1 antibody. The pathologist blinded to patient's background, scored the staining of FRG1 and micro-vessel density (MVD) count.

The expression levels of FRG1 protein in the cytoplasm and nucleus of tumor cells were scored as defined by Immunoreactive score, described by Fedchenko et al. [15]. MVD count was assessed as per Wiedner et al. [16]. Imaging and scoring were done using upright light microscope (CX31, Olympus, Japan), using 10X and 40X objective lenses.

\section{Plasmids, cell culture, transfection, reagents}

FRG1 expression vector (pCMV6.Xl5-FRG1) and knockdown vector (pLKO.1- FRG1sh) along with their controls were procured from Origene (USA) and Sigma (USA), respectively. Plasmids were purified using Plasmid midi kit (Qiagen) according to manufacturer's guidelines.

PC3 cells (ATCC CRL-1435 $^{\text {TM }}$ ) were obtained from National Centre for Cell Science (Pune, India) in 2015 and, were grown in RPMI1640 (HiMedia Labs, India) with 10\% FBS (Pan Biotech, Germany). DU145 (ATCC ${ }^{\circledR}$ HTB- $81^{\mathrm{TM}}$ ), a gift from Dr. Rajeeb Swain's Lab (Institute of Life sciences, Bhubaneswar, India) received in 2015, was 
grown in DMEM (Pan Biotech) with 10\% FBS. LNCaP cells (ATCC ${ }^{\oplus}$ CRL-1740 ${ }^{\mathrm{Tm}}$ ) were purchased from National Centre for Cell Science (Pune, India) in 2019. LNCaP cell line was found authentic, using AmpFLSTR Identifiler Plus PCR Amplification kit (Applied Biosystems, USA). DU145 and PC3 cell lines were found authentic, using AmpFLSTR Identifiler PCR Amplification kit (Applied Biosystems, USA). All the cell lines were tested for mycoplasma contamination (Lonza, MycoAlert Mycoplasma Assay Kit) and found free from it.

DU145 and PC3 cells were grown in DMEM (Pan Biotech) with $10 \%$ FBS. LNCaP cells were grown in RPMI (Himedia) with 15\% FBS. All the cell transfections were carried out using Lipofectamine 3000 (Invitrogen, USA), as per manufacturer's protocol. Cell lysate for FRG1 over-expression and knockdown conditions were prepared after $48 \mathrm{~h}$ and $72 \mathrm{~h}$ of transfection respectively, in both the cell lines. The pharmacological activator and inhibitor of p38 MAPK, Anisomycin (Calbiochem, USA) and SB203580 (Merck, USA) respectively, were used to modulate p38 MAPK activity in prostate cancer cells treated with FRG1 knockdown and scrambled sequence vectors. DU145 and PC3 cells were treated with $0.4 \mu \mathrm{g} / \mathrm{ml}$ Anisomycin (for $2 \mathrm{~h}$ and $6 \mathrm{~h}$ ) and $0.5 \mu \mathrm{M} \mathrm{SB} 203580$ (for $2 \mathrm{~h}$ ) and harvested for western blotting. Similarly, cells were harvested $8 \mathrm{~h}$ post-treatment for total RNA extraction.

\section{Western blot}

For cell lysate preparation, cells were washed with ice-cold phosphate-buffered saline (PBS) and lysed in ice-cold RIPA buffer (Thermo Fisher Scientific, USA), with added protease inhibitor (Sigma) and phosphatase inhibitor (Sigma). Protein quantification of cell lysate was done using BCA reagent (Thermo Fisher Scientific). $30 \mu \mathrm{g}$ of protein sample was mixed with equal volume of $2 \mathrm{X}$ Laemilli buffer and boiled at $95{ }^{\circ} \mathrm{C}$ for $10 \mathrm{~min}$. The lysates were separated on $10 \%$ sodium dodecyl sulfate-polyacrylamide gel electrophoresis (SDS-PAGE). The proteins, on the gels, were transferred to polyvinylidene fluoride (PVDF) membrane (Millipore, USA). The blots were probed with specific antibodies for FRG1 (1:1000 dilution) (Novus Biologicals, USA), ERK (1:1000) (Sigma), phospho ERK (1:1000), p38 MAPK (1:1000) (Cell Signaling Technology, USA), phospho p38 MAPK (1:1000) (Cell Signaling Technology) followed by HRP tagged anti-mouse IgG secondary antibody (Thermo Fisher Scientific) for FRG1 and, HRP tagged anti rabbit IgG secondary antibody for ERK, phospho ERK, p38 MAPK and, phospho p38 MAPK. The labeled bands were subsequently detected by chemiluminescence. For each sample, band intensities were normalized to GAPDH (1:10000) (Sigma).

\section{Cell proliferation assay}

LNCaP, PC3 and DU145 cells $\left(0.1 \times 10^{4}\right)$ were seeded in a 96 well plate. Cells were transfected with FRG1 expression and silencing vectors along with their respective controls. Transfected cells were grown for $96 \mathrm{~h}$. Afterwards culture medium was replaced with $100 \mu \mathrm{l}$ fresh medium and, $20 \mu \mathrm{l}$ of Cell titer 96 AQueous one solution reagent (Promega, USA) was added. Plates were incubated at $37^{\circ} \mathrm{C}$ for $1 \mathrm{~h}$. Absorbance was recorded at $490 \mathrm{~nm}$ wavelength using Varioskan multimode reader (Thermo Fisher Scientific).

\section{Wound healing assay}

PC3 and DU145 cells $\left(0.25 \times 10^{6}\right)$ were seeded into 6 well plates. Transfection was done with FRG1 expression and silencing vectors along their respective controls. Cells were allowed to grow till 100\% confluency. Scratch was made in the plate using a P200 pipette tip. Images were collected at $0 \mathrm{~h}$ and $24 \mathrm{~h}$ for PC3 and $0 \mathrm{~h}$ and $48 \mathrm{~h}$ for DU145, under inverted microscope (Ziess, Germany). Cell migration was analyzed using NIH imageJ software.

\section{Transwell migration assay}

Transwell migration assay was performed using Millipore transwell chambers $(8 \mu \mathrm{m}$ pore size, Millipore). PC3, DU145 and LNCaP cells $\left(2 \times 10^{4}\right.$ in each well), transfected with FRG1 expression vector and knockdown vector with their respective vector controls, were seeded in the upper chambers of the 12 well plate (Corning, USA) in $500 \mu \mathrm{l}$ serum-free medium. The lower chambers were filled with $1 \mathrm{ml}$ complete medium. The chamber was incubated at $37^{\circ} \mathrm{C}$ for $24 \mathrm{~h}(60 \mathrm{~h}$ for $\mathrm{LNCaP})$. At the end of incubation, the cells in the upper surface of the membrane were removed with a cotton swab. Cells in lower chamber were fixed with methanol and stained with Giemsa (HiMedia Labs). The images were taken with inverted microscope (CX41, Olympus) and analyzed using NIH imageJ software.

\section{Cell invasion assay}

Matrigel invasion assay and analysis was done as mentioned in transwell migration assay section. With an exception, in cell invasion assay, Millipore transwell chambers $(8 \mu \mathrm{m}$ pore size, Millipore) were coated with 1 $\mathrm{mg} / \mathrm{ml}$ growth factor reduced matrigel (Corning) prior to the assay.

\section{Q-RT-PCR}

Quantitative real time PCR was done to find out the effect of FRG1 expression on the expression of certain MMPs and cytokines. Three biological replicates of PC3 and DU145 cells with ectopic FRG1 expression and FRG1 knockdown along with their controls, were prepared. Total RNA was isolated with RNeasy mini kit (Qiagen) according to the manufacturers' protocol, concentration was measured using a NanoDrop 2000 spectrophotometer (Thermo Fisher Scientific). The RNA was 
converted to cDNA using the Superscript IV reverse transcriptase (Invitrogen). RNA extraction for cells treated with Anisomycin and SB203580 was performed after $8 \mathrm{~h}$ post treatment, using RNeasy minikit (Qiagen) followed by cDNA synthesis, using verso cDNA synthesis kit (Thermo Fisher Scientific).

qRT-PCR was performed for cytokines and MMPs, for which primers are mentioned in the (Additional file 1: Table S1), using the Fast start Universal SYBR Green master mix (Roche, Switzerland) with an ABI 7500 system (Applied Biosystems, USA). All the reactions were done in triplicate, using GAPDH as internal control.

\section{Statistical analysis}

Statistical analysis was performed using Graphpad Prism 7.00, Microsoft Excel and SPSS. For comparison of FRG1 expression in tumor versus uninvolved tissue, 2-tailed chi square test was applied to determine the significance. For chi square analysis IRS scores were recoded into negative (0-1), weak (2-3), moderate (4-8) and strongly positive (9-12), as described by Fedchenko et al. [15]. Fisher's exact test was carried out to associate negative (0-1) IRS score with tumor. Spearman correlation analysis was used to find out association of FRG1 IRS score with Gleason score in tumor samples and, with MVD. Student's t-test (2-tailed, unpaired) was performed to identify statistical significance in cell based assay data. We used SPSS (version 17) General linear model (GLM), univariate analysis, blocked by cell type and AR status, to find out the effect of FRG1 expression level, using combined data of all three cell types, on cell proliferation, migration and invasion. Regression and ANCOVA analysis was used to determine interaction of wound healing, migration and invasion. Q-Q plots were used to ascertain the normal distribution of data. $p$ value $\leq 0.05$ was considered to be significant in all the tests.

\section{Results}

\section{FRG1 levels in prostate adenocarcinoma}

FRG1 expression was analyzed in prostate cancer by immunohistochemistry in 20 needle core biopsies along with tissue array, consisting of 180 cores (including 90 paired tumor and uninvolved tissue). Out of 20 needle core biopsies, uninvolved prostate tissue was present in 10 biopsies. For prostate cancer samples, cohort information has been provided in (Additional file 2: Table S2). Figure 1a shows strong FRG1 staining in control tissue, compared to tumor tissue. The staining pattern revealed significant reduction of FRG1 expression levels in tumor cells, compared to uninvolved secretory ductal epithelial cells of prostate. Immunoreactive score (IRS), quantified for the staining pattern, revealed that 52 out of 100 cases $(p$ value $<0.0005)$ had reduced FRG1 expression in tumor tissue (Fig. 1b). FRG1 staining was negative in $39 \%$ of tumor tissue compared to
$14 \%$ of uninvolved tissue. Fisher's exact test (2-sided, $\mathrm{df}=1$ ) showed significant $(p<0.0001)$ association of negative IRS score with tumor. Staining pattern of FRG1 was mostly moderate to weak in both tumor and uninvolved tissue, with $22 \%$ weak in tumor to $40 \%$ weak expression in uninvolved tissue. Moderate staining was distributed evenly with $37 \%$ tumor cases showing moderate staining, compared to $40 \%$ cases of uninvolved tissue. $6 \%$ uninvolved tissue had high FRG1 staining compared to $2 \%$ of tumor tissue (Fig. 1c). FRG1 expression (IRS) showed significant negative correlation (Spearman correlation, 2-tailed, $\mathrm{r}^{2}-0.285, p$ value < 0.005 ) with tumor grade (Gleason score) (Additional file 3 ).

Further, to understand the effect of FRG1 expression on tumor angiogenesis, correlation analysis was done for FRG1 IRS and MVD. No significant correlation (Spearman correlation, 2-tailed) could be derived between FRG1 protein expression levels and MVD ( $p$ value > $0.05, \mathrm{r}^{2}$ 0.105) (Additional file 3). Overall, patient IHC data revealed that FRG1 expression is reduced in tumor tissue but does not correlate with MVD count.

\section{FRG1 expression doesn't correlate with AR status in prostate cancer cell lines}

To find out if there is any prostate cancer cell line specific expression pattern of FRG1, the endogenous FRG1 expression levels were determined in PC3, LNCaP, and DU145 cells. PC3 and LNCaP cells had higher FRG1 expression compared to DU145 (Fig. 1d). As PC3 and DU145 are androgen receptor negative cells and LNCaP is androgen receptor positive, FRG1 expression cannot be correlated with the presence of receptor.

\section{Varying effect of FRG1 on proliferation of AR negative prostate cancer cells}

To find out if FRG1 has any direct effect on proliferation, we prepared DU145 and PC3 cells with ectopic expression of FRG1 and with depletion of FRG1, along with their controls (Fig. 1e-h). Cell proliferation assay revealed that FRG1 over-expression had no significant effect on proliferation of DU145 cells (Fig. 2a) but FRG1 knockdown led to significant increase in cell proliferation (Fig. 2b). PC3 cells had significantly reduced proliferation in response to ectopic expression of FRG1 (Fig. 2c) but no significant effect was observed on cell proliferation of PC3 cells with FRG1 knockdown (Fig. 2d).

\section{FRG1 affects motility and invasiveness in AR negative prostate cancer cells}

Enhanced cell motility and invasiveness are important features of tumor progression. Therefore, to investigate the role of FRG1 in cell migration and invasion we performed scratch wound healing, transwell cell migration and matrigel invasion assays. 


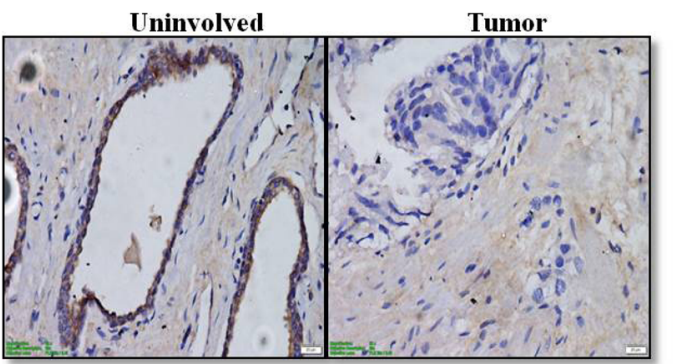

A

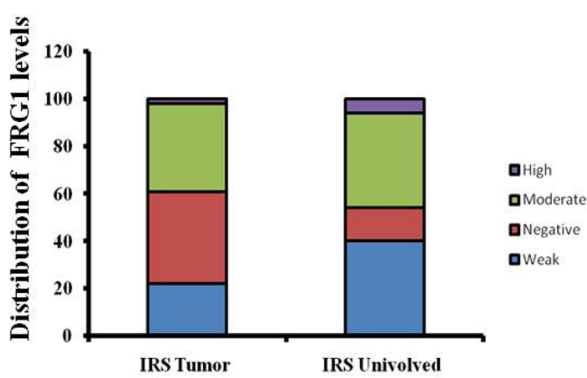

C

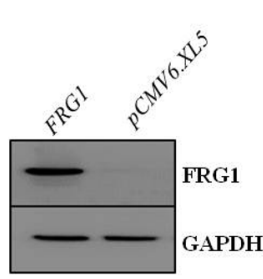

$\mathbf{E}$

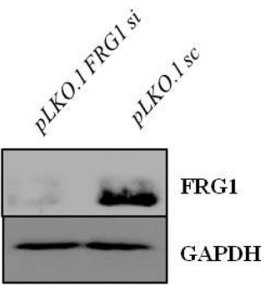

F
B
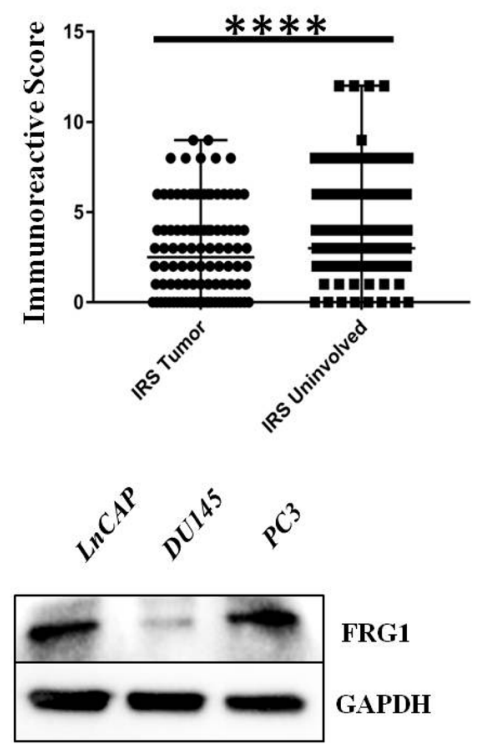

D

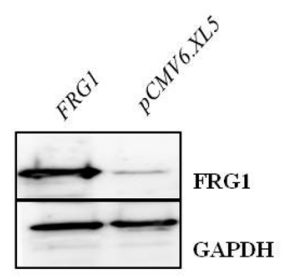

G

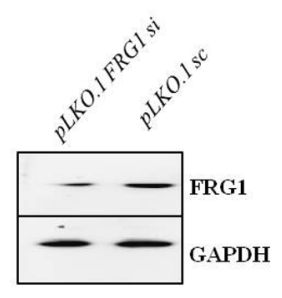

H

Fig. 1 FRG1 expression levels in prostate tumor and cell lines: a. Representative images of tumor and uninvolved tissues of prostate, as seen in first (uninvolved) and second (tumor) column from left. b. Comparison of IRS between tumor and uninvolved tissue. Graph shows that the reduction of IRS in tumor tissue $(N=100)$ compared to uninvolved adjacent tissue $(N=100)$ was significant (chi square test, 2 tailed, df-5, $p$ value $<0.0005)$. Median IRS score for FRG1 in tumor is 2.5 compared to adjacent uninvolved tissue, which is 3.5. c. Distribution of staining pattern for FRG1 in the prostate tumor ( $N=100$ ) and uninvolved tissue $(N=100)$. d. FRG1 expression levels in three different prostate cancer cells, western blot panel shows comparatively higher levels of FRG1 in PC3 and LNCaP than DU145 cells. e. Western blot to confirm ectopic expression of FRG1 in DU145 cells. f. Western blot showing reduced FRG1 levels after RNAi silencing in DU145. g. Western blot image validating ectopic expression of FRG1 levels in PC3 cells. $\mathbf{h}$. Reduction in FRG1 levels in FRG1 silenced PC3 cells confirmed by western blot. ${ }^{* * *}$ represents $p$ value $<0.0005$, N represents number of patient samples

Wound healing was significantly $(p$ value $<0.05)$ reduced in cells ectopically expressing FRG1, with $52 \%$ area healed in FRG1 expression set compared to $74 \%$ of empty vector, in DU145. In PC3 cell line, FRG1 expression led to 57\% area being healed, compared to $90 \%$ of empty vector set ( $p$ value $<0.05$ ) (Fig. 2e-f, i-j, respectively). To confirm the findings, scratch wound healing assay was done in FRG1 knockdown set. Increased wound healing in FRG1 knockdown set was observed, compared to scrambled control vector set (91\% vs. $68 \%$ respectively, $p$ value $<0.05$ ) in DU145 (Fig. $2 g$-h). In PC3 cells, FRG1 knockdown led to $80 \%$ reduced wound area compared to $70 \%$ of scrambled vector set $(p$ value $<0.005)$ (Fig. 2k-l).

Further support was provided by transwell cell migration data, which was decreased in cells ectopically expressing FRG1, compared to empty vector control, in both DU145 ( $p$ value $<0.01)$ and PC3 $(p$ value $<0.005)$ cell lines (Figs. 3a-b and 4e-f, respectively). This observation was reversed when FRG1 expression was silenced, in both DU145 ( $p$ value $<0.05)$ and PC3 ( $p$ value $<0.01)$ (Figs. 3c-d and 4g-h, respectively). Ectopic expression of FRG1 led to significant reduction in cell invasion in both DU145 ( $p$ value $<0.05)$ and PC3 $(p$ value $<0.05)$ cells (Figs. 3i-j and 4m-n, respectively). FRG1 knockdown had opposite effect on cell invasion, as FRG1 knockdown led to increase in cell invasion in both DU145 ( $p$ value < 0.05 ) and PC3 ( $p$ value $<0.05$ ) cells (Figs. 3k-l and 4o-p, respectively). These results clearly indicate that FRG1 reduces cell migration and invasion in prostate cancer cells in vitro. 


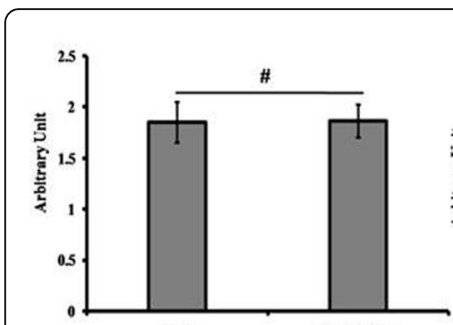

A FRG1

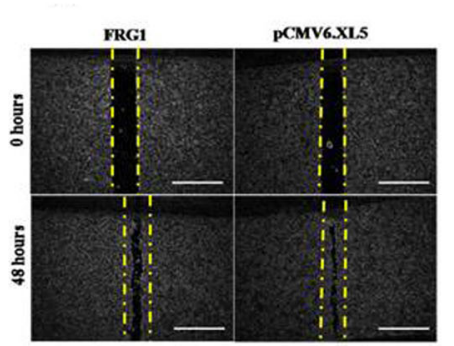

E

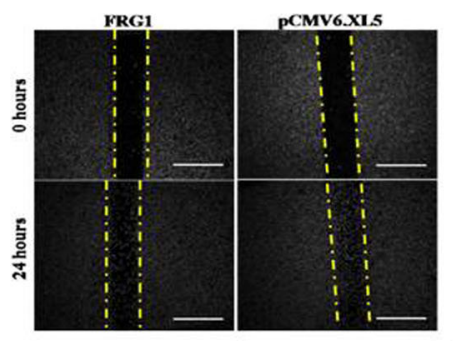
I

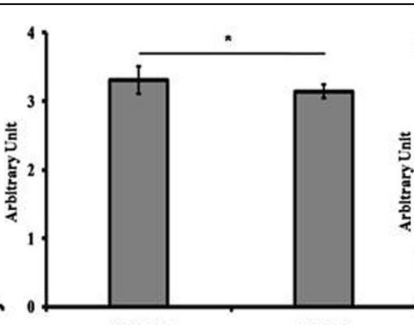

B

FRG1 KD

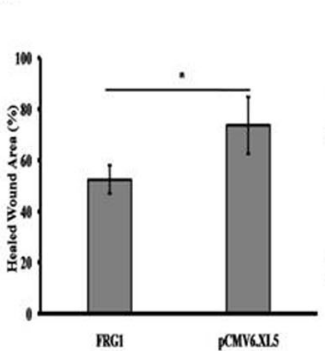

F

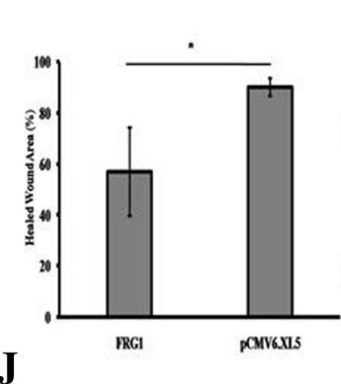

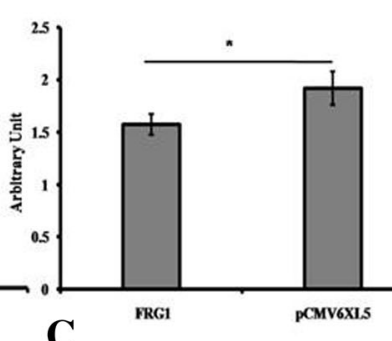

C

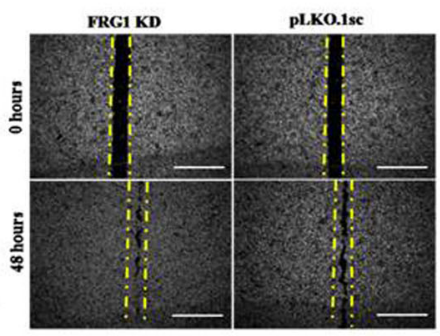

G

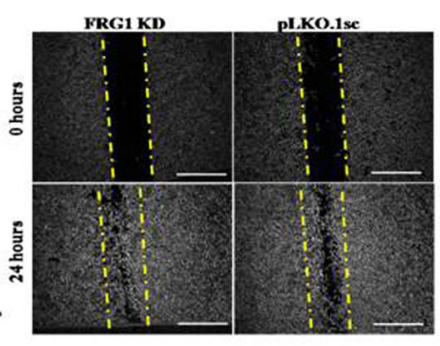

K

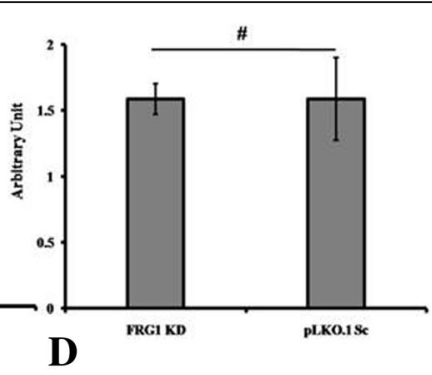

D

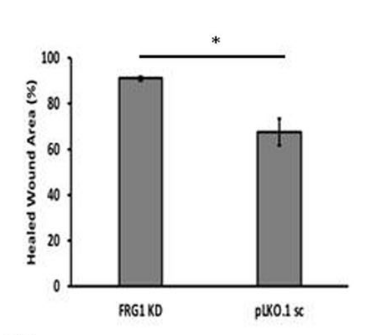

H

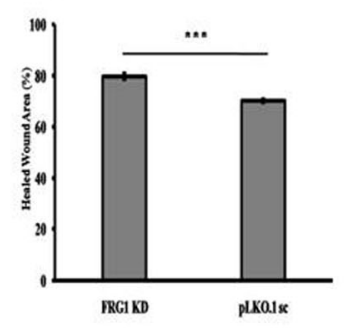

L 2-tailed unpaired t-test, $p$ value $>0.05$ ) effect on cell proliferation in DU145, compared to empty vector control. b. Measurement of cell proliferation in DU145, knockdown of FRG1 showing significant increase in cell proliferation ( $N=5$, 2-tailed unpaired t-test, $p$ value $<0.05)$, compared to scrambled vector control. c. Measurement of cell proliferation in PC3 with ectopic expression of FRG1, compared to empty vector control, showing significant reduction $(N=5$, 2-tailed unpaired t-test, $p$ value < 0.05). d. Quantitation of cell proliferation in PC3 with knockdown of FRG1, compared to scrambled vector control, showing no significant ( $N=5$, 2-tailed unpaired t-test, $p$ value $>0.05$ ) effect. e. Representative images of scratch wound healing assay of DU145 cells, with ectopic expression of FRG1 and respective vector control. f. Graph of scratch wound healing assay of DU145 cells with ectopic expression of FRG1, showing 52\% reduced wound area, compared to empty vector control with 74\% reduced wound area ( $N=3$, 2-tailed unpaired t-test, $p$ value < 0.05$)$. g. Representative images of scratch wound healing assay of DU145 with FRG1 knockdown and respective scrambled vector control. h. Graph of scratch wound healing assay of DU145 cells with FRG1 knockdown showing 91\% reduced wound area, compared to scrambled vector control with 68\% reduced wound area $(N=3$, 2-tailed unpaired t-test, $p$ value < 0.05). i. Representative images of scratch wound healing assay of PC3 cells with ectopic expression of FRG1 and respective vector control. j. Graph of scratch wound healing assay of PC3 cells with ectopic expression of FRG1, showing 57\% reduced wound area, compared to empty vector control with $90 \%$ reduced wound are ( $N=3$, 2-tailed unpaired t-test, $p$ value $<0.05)$. $\mathbf{k}$. Representative images of scratch wound healing assay of PC3 with FRG1 knockdown and respective scrambled vector control. I. Graph of scratch wound healing assay of PC3 cells with FRG1 knockdown, showing $80 \%$ reduced wound area, compared to scrambled vector control with 70\% reduced wound area $(\mathrm{N}=3,2$-tailed unpaired t-test, $p$ value $<0.005$ ). \# represents $p$ value $>0.05$, * represents $p$ value $\leq 0.05,{ }^{* *}$ represents $p$ value $<0.01,{ }^{* * *}$ represents $p$ value $<0.005, \mathrm{~N}$ represents experiment replicates

\section{No effect of FRG1 expression on cell properties of AR positive cell line}

To figure out if the effect of FRG1 expression on prostate cancer cells is irrespective of androgen receptor status, we used LNCaP cell lines with ectopic expression of FRG1 and depletion of FRG1 along with their controls (Fig. 4a), for cell based assays. We found that FRG1 ectopic expression didn't change proliferation (Fig. 4b), migration (Fig. 4d-e) or invasion (Fig. 4h-i) properties of LNCaP cells significantly ( $p$ value $>0.05$ ), compared to its control. Similarly, depletion of FRG1 expression didn't change proliferation (Fig. 4c), migration (Fig. 4f-g) or invasion (Fig. $4 \mathrm{j}-\mathrm{k}$ ) properties of $\mathrm{LNCaP}$ cells ( $p$ value $>0.05)$. These results indicate that the effect of FRG1 expression is cell line specific and might be dependent upon androgen receptor status. 


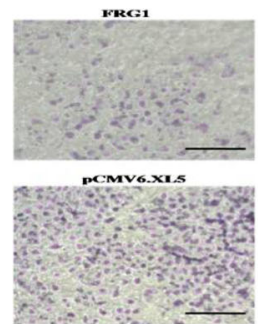

A

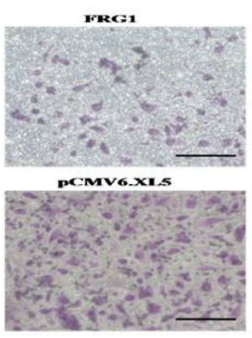

E

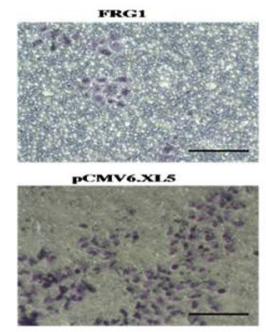

I

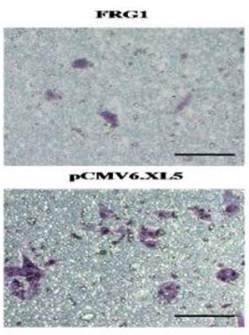

M

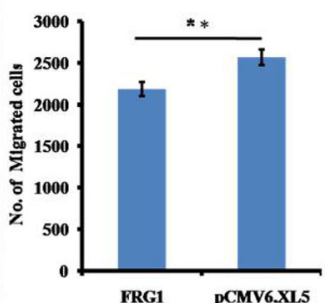

B

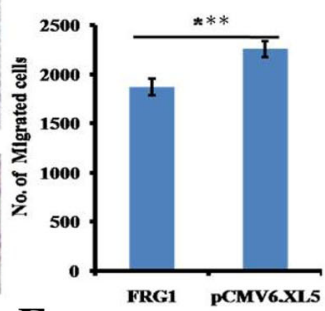

F

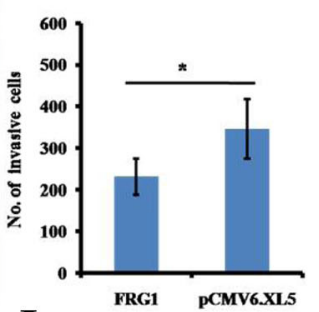

J

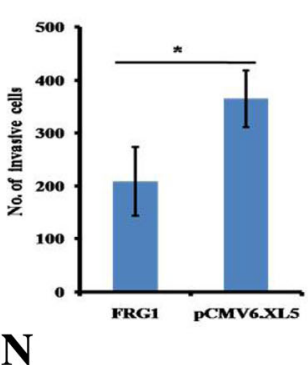

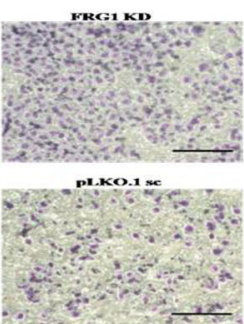

C

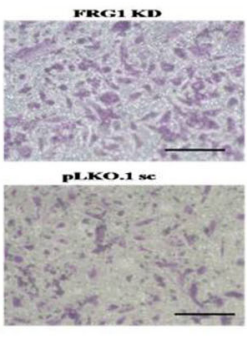

G

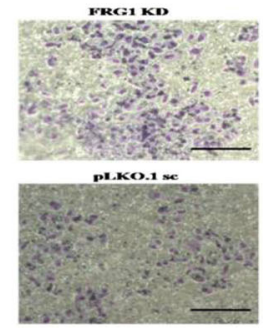

K

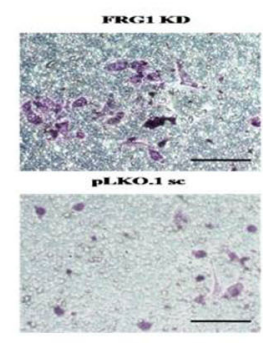

O

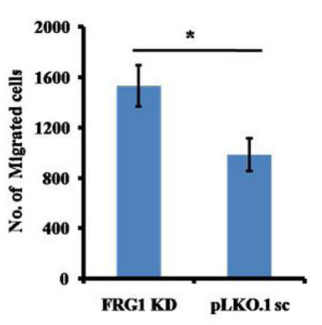

D

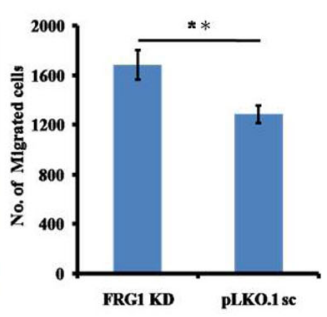

H

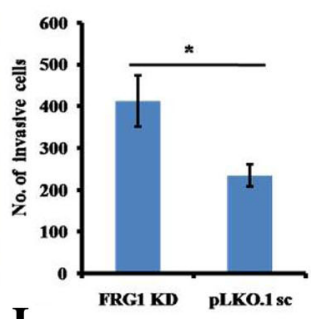

L

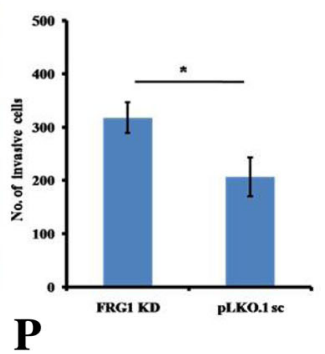

Fig. 3 (See legend on next page.) 


\begin{abstract}
(See figure on previous page.)
Fig. 3 Effect of FRG1 expression on transwell migration and invasion: a. Representative images of transwell migration assay of DU145 cells with ectopic expression of FRG1 and respective vector control. b. Graphical representation of transwell migration assay of DU145 cells with ectopic expression of FRG1 (2183 \pm 84), showing reduction in transwell migration, compared to empty vector control (2565 \pm 94$)(\mathrm{N}=3$, 2-tailed unpaired t-test, $p$ value $<0.01)$. c. Representative images of transwell migration assay of DU145 cells with FRG1 knockdown and respective scrambled vector control. d. Graph of transwell migration assay of DU145 cells with FRG1 knockdown (1532 \pm 165 ), showing enhanced transwell migration, compared to scrambled vector control $(987 \pm 130)(N=3$, 2-tailed unpaired t-test, $p$ value $<0.05)$. e. Representative images of transwell migration assay of PC3 cells with ectopic expression of FRG1 and respective vector control. $\mathbf{f}$. Graphical representation of transwell migration assay of PC3 with ectopic expression of FRG1 $(1869 \pm 86)$, showing reduction ( $N=3$, 2-tailed unpaired t-test, $p$ value $<0.005)$ in transwell migration, compared to empty vector control $(2256 \pm 81)$. g. Representative images of transwell migration assay of PC3 cells with FRG1 knockdown and respective scrambled vector control. h. Graphical representation of transwell migration assay of PC3 cells with FRG1 knockdown (1685 \pm 120 ), showing enhanced ( $N=3$, 2-tailed unpaired t-test, $p$ value $<0.01)$ transwell migration, compared to scrambled vector $(1285 \pm 71)$. i. Representative images of matrigel invasion assay of DU145 cells with ectopic expression of FRG1 and respective vector control. j. Graphical representation of matrigel invasion assay of DU145 cells with ectopic expression of FRG1 (231 \pm 43 ) compared to empty vector control (357 \pm 60$)(\mathrm{N}=3,2$-tailed unpaired ttest, $p$ value $<0.05)$. $\mathbf{k}$. Representative images of matrigel invasion assay of DU145 with FRG1 knockdown and respective scrambled vector control. I. Representative graph of matrigel invasion assay of DU145 cells with FRG1 knockdown (412 \pm 62 ) compared to scrambled vector control (234 \pm 27 ) ( $N$ $=3$, 2-tailed unpaired t-test, $p$ value < 0.05). $\mathbf{m}$. Representative images of matrigel invasion assay of PC3 cells with ectopic expression of FRG1 and respective vector control. $\mathbf{n}$. Representative graph of matrigel invasion assay of PC3 cells with ectopic expression of FRG1 (208 \pm 65 ) compared to empty vector control (365 \pm 53$)(N=3$, 2-tailed unpaired t-test, $p$ value $<0.05)$. o. Representative images of matrigel invasion assay of PC3 with FRG1 knockdown and respective scrambled vector control. p. Representative graph of matrigel invasion assay of PC3 cells with FRG1 knockdown (318 \pm 29 ) compared to scrambled vector control $(207 \pm 37)(N=3$, 2-tailed unpaired t-test, $p$ value $<0.05)$. ${ }^{*}$ represents $p$ value $\leq 0.05$, ${ }^{* *}$ represents $p$ value $<$ $0.01, * * *$ represents $p$ value $<0.005, \mathrm{~N}$ represents experiment replicates
\end{abstract}

\section{Collectively three cell lines show significant effect of} FRG1 expression level on cell migration and invasion To figure out the general effect of FRG1 expression of cell properties we combined the data of three cell lines and used GLM, univariate test and blocked by cell type and AR status. We found that FRG1 expression doesn't affect cell proliferation significantly ( $p$ value $>0.05)$. However, ectopic expression affected the migration ( $p$ value $<0.0005)$ and invasion $(p$ value $<0.05)$ of prostate cancer cell lines significantly. Likewise, knock down of FRG1 led to significant difference in rate of migration ( $p$ value $<0.0001)$ and invasion $(p$ value $<0.0001)$. We didn't find any interaction between migration (wound healing and transwell migration) and invasion ( $p$ value $>$ 0.05).

\section{FRG1 expression level dictates expression of various cytokines and MMP1}

To identify the associated cytokines affected by FRG1 expression, q-RT PCR analysis for 13 cytokines and 7 Matrix metalloproteinases was done (see additional file 1 for primer information). These cytokines have previously been reported to affect cellular phenotypes, i.e. proliferation, migration, invasion and angiogenesis. Ectopic expression of FRG1 led to no significant change in expression of cytokine and matrix metalloproteinases, in both DU145 and PC3 cells (Additional file 4). On the other hand, FRG1 knockdown showed significant change in expression of certain targets in cell line specific manner. FRG1 knockdown in DU145 led to significant increase in expression of GM-CSF (fold change $=1.51, p$ value $<0.0005$ ), PLGF (fold change $=2.04, p$ value $<0.0005$ ) and MMP1 (fold change $=1.83, p$ value $<0.01$ ) (Fig. 5a). By FRG1 silencing in PC3 cells, expression of GM-CSF (fold change $=3.022$, $p$ value $<0.0005$ ), MMP1 (fold change $=1.56, p$ value $<$ 0.01 ), PDGFA (fold change $=1.58, p$ value $<0.0005$ ) and CXCL1 (fold Change $=1.67, p$ value $<0.0005$ ) showed significant increase in expression (Fig. 5b). Here we can infer that FRG1 may affect proliferative, migratory and invasiveness properties of cells by modulating expression of above mentioned cytokines and MMPs.

\section{FRG1 silencing enhances p38 MAPK activation}

To identify effect of FRG1 expression on key signaling pathways we checked the activation levels of ERK and p38 MAPK. FRG1 knockdown showed enhanced phosphorylation of p38 MAPK, in both PC3 and DU145 cells (Fig. 6a-b). On the contrary, no significant difference was observed on ERK phosphorylation levels during FRG1 knockdown in DU145 but slightly elevated levels of phospho ERK were observed in PC3 cells (Fig. 6a-b). Since ERK phosphorylation was neither prominent nor consistent, it was not taken up for further study.

To further confirm the specificity of p38 activation by FRG1 knock down, we transfected FRG1 depleted DU145 and PC3 cells, with FRG1 expression vector. We observed that effect of FRG1 depletion on p38 activation, is rescued in both DU145 (Fig. 6c) and PC3 cells (Fig. 6d).

\section{FRG1 regulates cytokine expression via p38 MAPK}

To validate that FRG1 dictates change in expression of cytokines and MMPs (GM-CSF, PLGF and MMP1 in DU145 and, GM-CSF, PDGFA, MMP1 and CXCL1 in PC3 cells), through p38 MAPK, firstly p38 MAPK was activated in DU145 and PC3 cells and, change in expression of previously mentioned cytokines and MMPs was checked by qRT-PCR. In DU145 cells, activation of the 


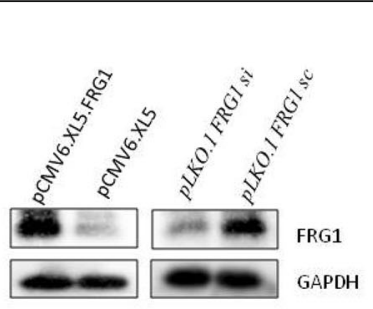

A

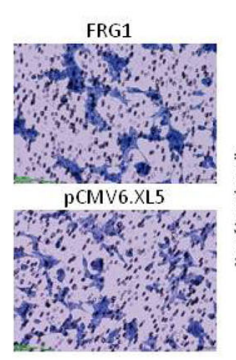

D

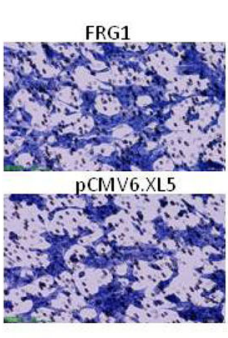

H

E

I

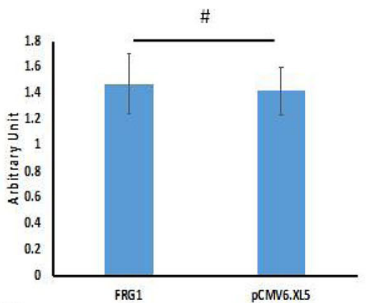

B
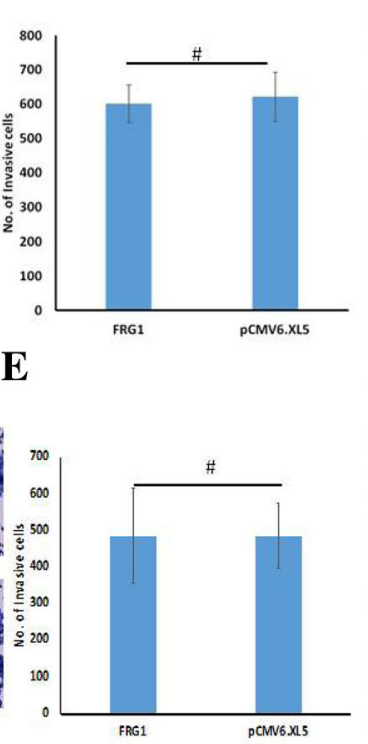

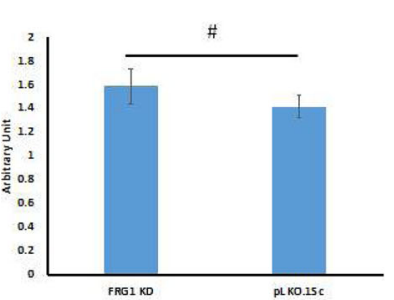

C
FRG1 KD

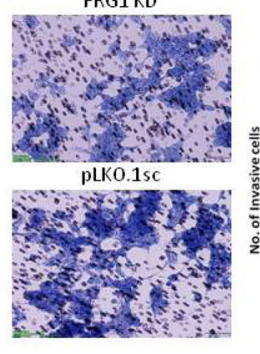

F

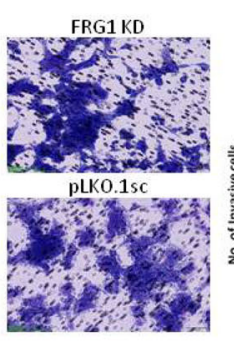

J

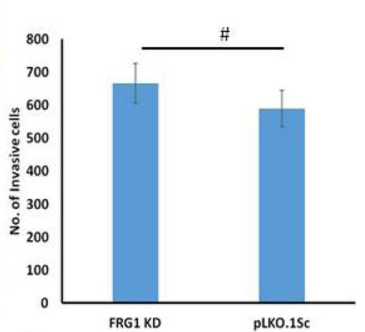

G

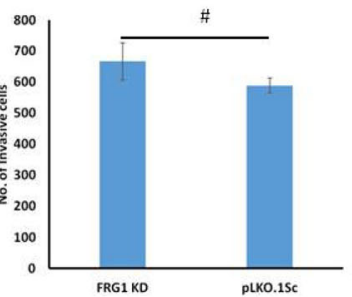

K

Fig. 4 Effect of FRG1 expression on LNCaP cell properties. a. Western blot to confirm ectopic expression of FRG1 in LNCaP cells. Western blot to confirm depletion of FRG1 expression in LNCaP cells after RNAi silencing. $\mathbf{b}$. Graphical representation of LNCaP cell proliferation assay showing that ectopic expression of FRG1 has no significant $(N=5$, 2-tailed unpaired t-test, $p$ value $>0.05)$ effect on cell proliferation, compared to empty vector control (pCMV6.XL5). c. Graph showing that knockdown of FRG1 (FRG1 KD) doesn't change LNCaP cells proliferation significantly ( $N=5$, 2tailed unpaired t-test, $p$ value $>0.05$ ), compared to control (pLKO.1sc). d. Representative images of transwell migration assay of LNCaP cells with ectopic expression of FRG1 (FRG1) and respective vector control (pCMV6.XL5). e. Graphical representation of transwell migration assay of LNCaP cells with ectopic expression of FRG1 (601 \pm 54$)$, showing no change in transwell migration, compared to empty vector control $(622 \pm 71)(N=3$, 2-tailed unpaired t-test, $p$ value $>0.05$ ). $\mathbf{f}$. Representative images of transwell migration assay of LNCaP cells with FRG1 knockdown (FRG1 KD) and respective scrambled vector control (pLKO.1sc). g. Graph of transwell migration assay of LNCaP cells with FRG1 knockdown (645 \pm 61 ), showing no change in transwell migration, compared to scrambled vector control $(550 \pm 55)(\mathrm{N}=3$, 2-tailed unpaired t-test, $p$ value $>0.05)$. $\mathbf{h}$. Representative images of matrigel invasion assay of $\mathrm{LNCaP}$ cells with ectopic expression of FRG1 and respective vector control. i. Graphical representation of matrigel invasion assay of LNCaP cells with ectopic expression of FRG1 (483 \pm 130$)$ compared to empty vector control $(484 \pm 89)(N=3,2$-tailed unpaired t-test, $p$ value $>0.05$ ). j. Representative images of matrigel invasion assay of LNCaP cells with FRG1 knockdown (FRG1 KD) and respective scrambled vector control (pLKO.1sc). k. Representative graph of matrigel invasion assay of LNCaP cells with FRG1 knockdown (666 \pm 60 ) compared to scrambled vector control $(589 \pm 24)(N=3,2$-tailed unpaired t-test, $p$ value $>0.05)$. \# represents $p$ value $>0.05, N$ represents experiment replicates

p38 MAPK via Anisomycin treatment (Fig. 7a) increased the expression of GM-CSF and PLGF but MMP1 levels were not altered (Fig. 7c). Similarly, in the PC3 cells, p38 MAPK activation (Fig. 7b) increased the expression of GM-CSF, MMP1 and CXCL1 but not of PDGFA (Fig. 7d).

For further validation of FRG1's effect on cytokines and MMPs expression, p38 MAPK was inhibited in DU145 and PC3 cells, with or without FRG1 knockdown. Inhibition of p38 levels in DUI45 cells with FRG1 knockdown, (Fig. 8a) led to the reduction of GM-CSF and PLGF levels but MMP1 levels remained unaltered, compared to DUI45 cells with FRG1 knockdown (Fig. 8c). Inhibition of p38 MAPK in PC3 cells with FRG1 knockdown (Fig. 8b), led to the reduced expression of GM-CSF, MMP1, CXCL1 and PDGFA, compared to PC3 cells with FRG1 knockdown (Fig. 8d). Overall, we found that FRG1 expression levels affect expression of GM-CSF and PLGF in DU145 cell via p38 MAPK. MMP1 expression alteration is not mediated via p38 MAPK. Data in PC3 suggests that FRG1 expression 

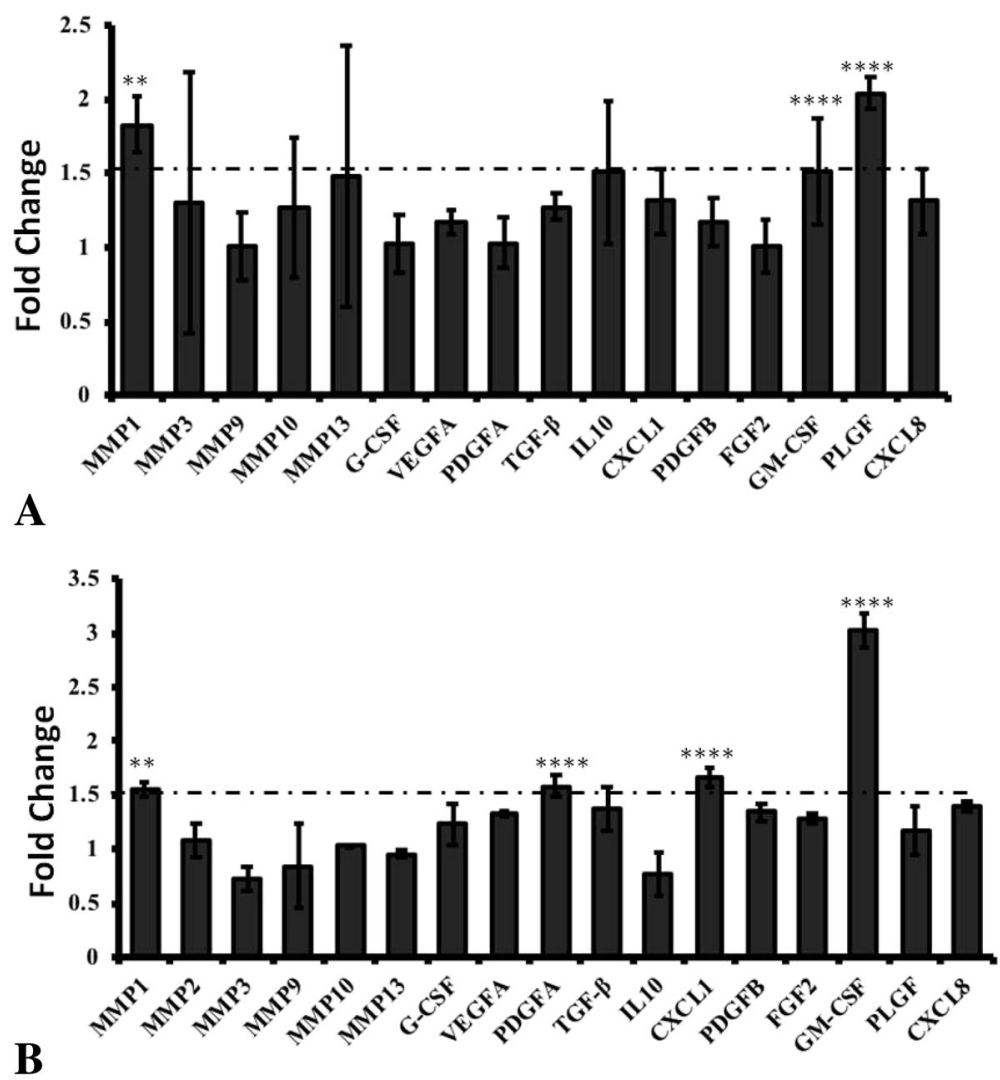

Fig. 5 Expression analysis of cytokines and MMPs: a. q-RT PCR expression analysis of genes listed in Additional file 1 in DU145 cells, transfected with FRG1 silencing vector compared to scrambled vector control, b. q-RT PCR expression data of genes listed in Additional file 1, in PC3 cells with knockdown for FRG1 versus scrambled vector control. In panel A and B, t-test (2 tailed, for unpaired samples) was used for comparison of fold change values between experimental and control group. Each experimental group had three replicates. Dotted line represents 1.5 -fold cut off, ** represents $p$ value $<0.01,{ }^{* * * *}$ represents $p$ value $<0.0005$

alters, expression of GM-CSF, MMP1 and, CXCL1 via p38 MAPK. Effect on PDGFA expression was not consistent.

These findings suggest that FRG1 might dictate cellular processes through specific cytokines and MMPs via modulation of p38 activity in cell specific manner.

\section{Discussion}

Studies about FRG1 are primarily focused on FSHD pathophysiology and muscle development $[17,18]$. Functional studies have shown FRG1 to be actin bundling and RNA binding protein $[19,20]$, accordingly claiming that FRG1 localizes in both, cytoplasm and nucleus. Our study first time revealed FRG1 expression level and localization in prostate cancer tissue and, showed the significant loss of FRG1 expression in tumor tissues. FRG1 expression was predominantly cytoplasmic but sporadic cases with nuclear localization were also observed. FRG1 expression levels regulate angiogenesis during Xenopus development by affecting dab2 levels [6]. In our study, no significant association between FRG1 expression and angiogenesis was observed. Involvement of FRG1 in angiogenesis remains unclear as
FSHD patients with retinal vasculature abnormalities, showed no change in FRG1 expression [21]. Thus, a well stratified and higher sample size could provide a more conclusive picture regarding localization and role of FRG1 in tumor angiogenesis.

Our study for the first time demonstrates the effect of FRG1 expression on cell properties viz. proliferation, migration and invasion, which are important for tumorigenesis. Prior reports of FRG1 affecting cellular migration, was of myoblast cells in Xenopus development, where FRG1 over-expression enhanced migration and invasion [18]. On the contrary, in our data FRG1 knockdown enhanced cell migration in prostate cancer cells in vitro. Which is supported by prior study, where reduced expression of FRG1 was observed in breast cancer cells with higher migratory levels, compared to average non-migratory breast cancer cells [22]. This observation suggests role of FRG1 in migration but in opposite way, indicating that FRG1 function may vary in tumor and developmental set up. Earlier reports have also shown that FRG1 over-expression reduces cell proliferation of mice myoblasts [23]. With varying effect of 


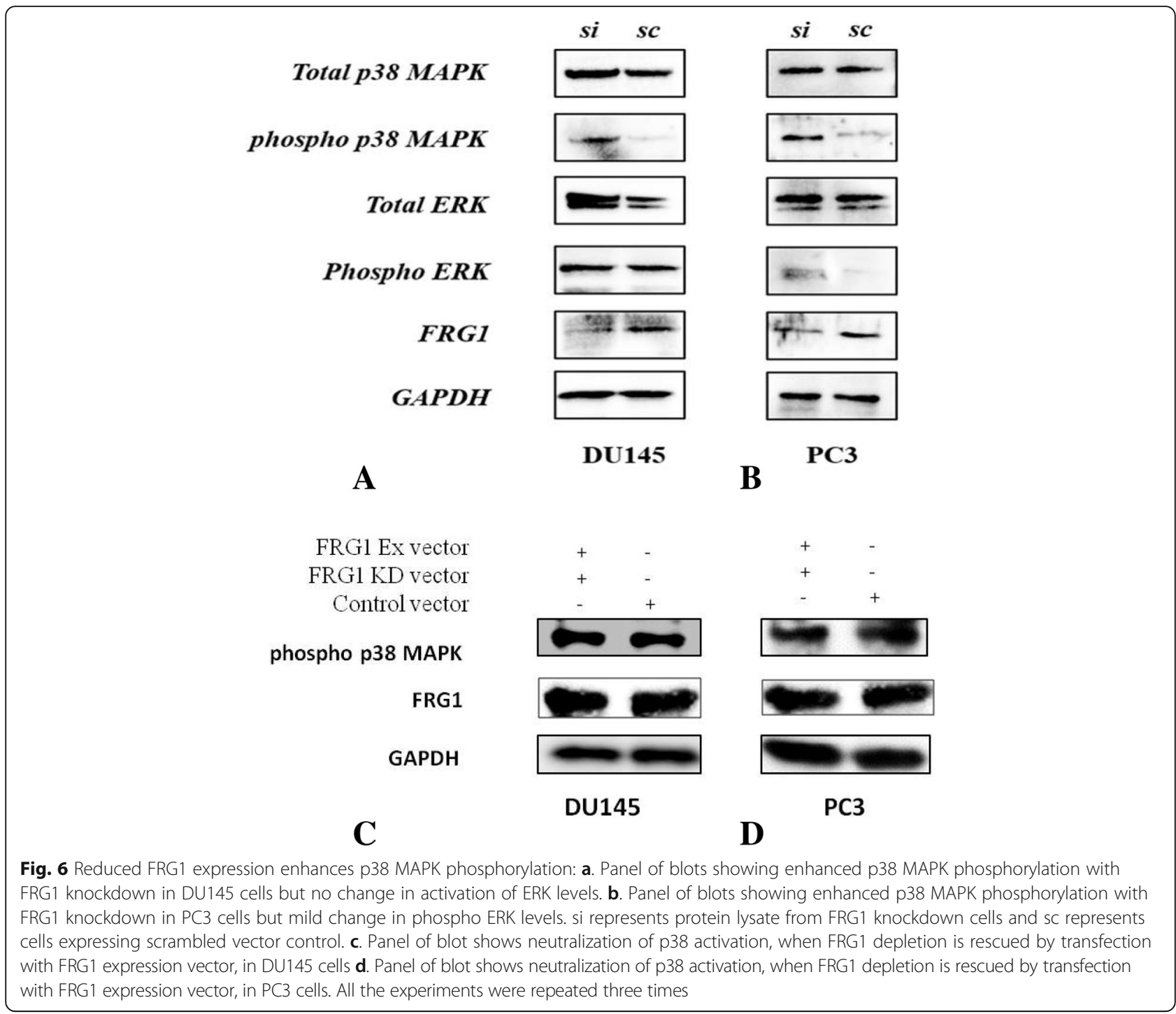

FRG1 levels in these cell types, an argument can be placed that FRG1 may have discrete effect on various cell types and may dictate cellular properties based on the stromal components.

We found that effect of FRG1 on migration and invasion is also cell type specific. In AR positive LNCaP cells, FRG1 doesn't effect migration or invasion. This observation can either be attributed to interaction of FRG1 with androgen receptor mediated signaling or to the other differences present in LNCaP cells, compared to DU145 or PC3. Expression pattern of cell surface molecules is similar for both DU145 and PC3 than for LNCaP. DU145 and PC3 cell lines retain cell surface markers such as CD49b/f, CD55 [24] which are reported to have potent role in cancer metastasis [25] [26] [27], through interaction of several pathways, whereas LNCaP cell line lacks these markers, which might be a possible reason for low invasion, migration, proliferation property of
LNCaP. Biological function and gene expression is also reported to be similar in DU145 and PC3 [24]. Additionally, LNCaP possesses the differentiated characteristic of prostate secretory cells, in terms of producing prostate-specific antigen and response to androgen regulation; PC3 and DU145 do not show such feature. Moreover, DU145 and PC3 cells are considered to represent more advanced stage of prostate cancer than LNCaP [24] which can justifies more proliferation, invasion, migration property of DU145 and PC3 than LNCaP. Overall, further investigation is required to figure out, why FRG1 expression has no effect in LNCaP cell properties.

FRG1 over-expression had no effect on expression levels of cytokines and MMPs but FRG1 knockdown, in both the prostate cancer cell lines, led to enhanced expression of MMP1, GM-CSF, PLGF, PDGFA and CXCL1 in DU145 and PC3. MMP1 and GM-CSF were up-regulated in both DU145 and PC3 cell lines. FRG1 


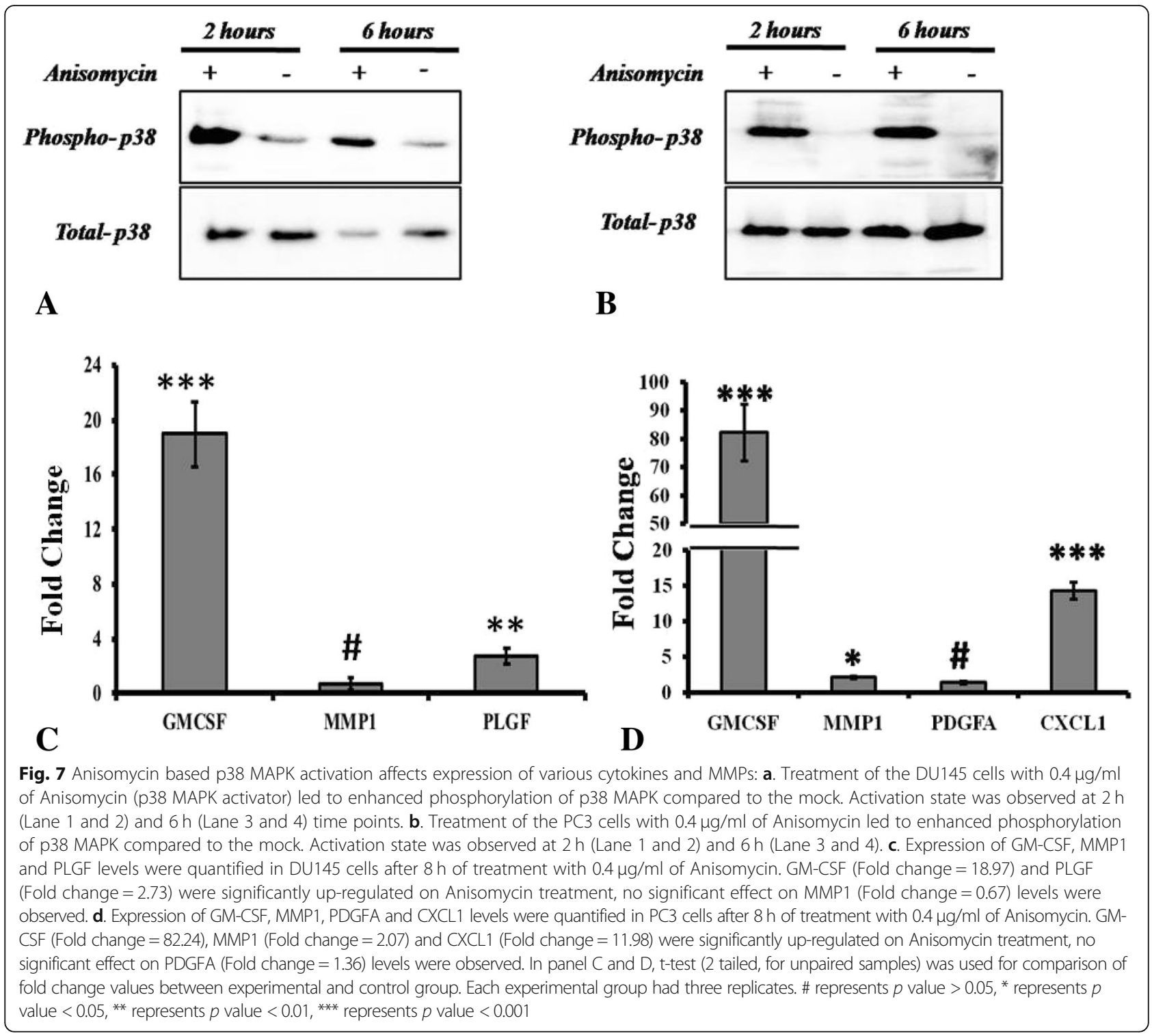

knockdown led to activation of p38 MAPK; activation of p38 MAPK has been associated with tumor progression previously [28]. In prostate cancer p38 MAPK activation has been reported via TNF $\alpha$ and IL6 [28, 29]. We are first time reporting the involvement of FRG1 in p38 MAPK mediated signaling, which can be very well connected with our data on various cytokines expression and explains the results of cell based assays. We found that GM-CSF was up-regulated in both DU145 and PC3 cell lines, with reduced FRG1 expression; earlier study has shown that both these cell lines are positive for GM-CSF receptor [30]. Treatment of DU145 and PC3 cells with GM-CSF has been shown to enhance colonogenicity and chemotaxis [30]. Up-regulation of GM-CSF with FRG1 knockdown in prostate cancer cells might be one of the factors affecting cell migration and invasiveness. Prior studies in human monocytes and bronchial epithelial cells have observed that p38 MAPK activation regulates GM-CSF production [31]. In this study, we have clearly shown that GM-CSF levels are altered with activation and inhibition of p38 MAPK. CXCL1 is known to enhance tumor stromal interaction leading to enhanced migration and invasion in various cancer [32]. With respect to prostate cancer, CXCL1 is known to affect cell migration and invasion via $\mathrm{NFkB} /$ HDAC [33]. TNF alpha enhances p38 phosphorylation in endothelial cells which up-regulates CXCL1 levels (20). Here we report that FRG1 knockdown leads to p38 activation in prostate cancer cells affecting CXCL1 expression, which is well supported by previous studies, except the role of FRG1. Activation of p38 MAPK also induces expression of MMP1, promoting invasiveness in 


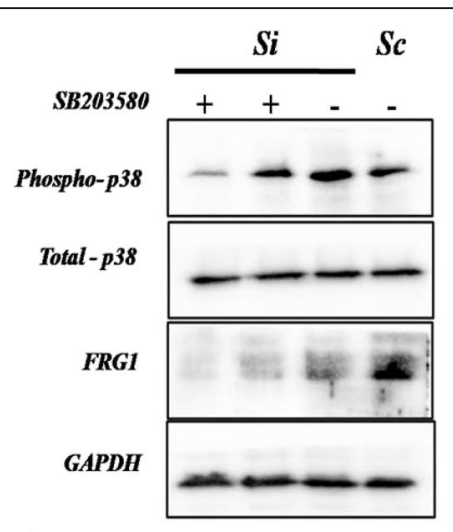

A

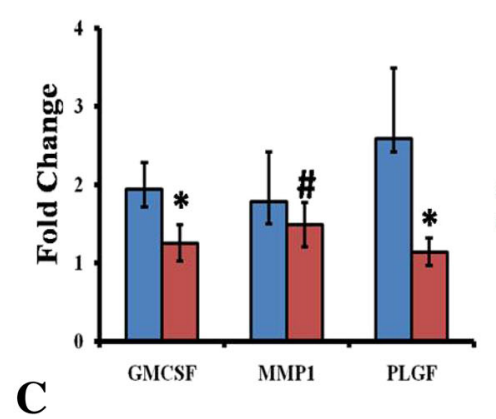

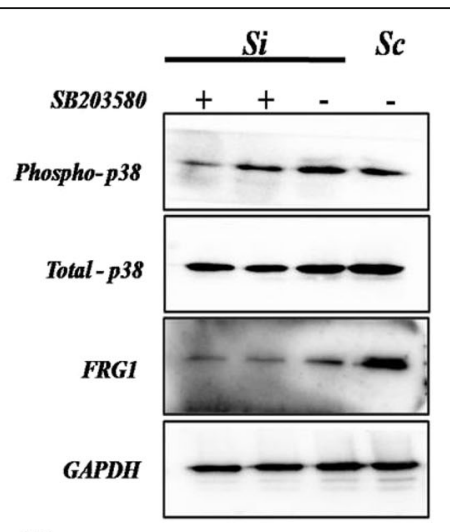

B

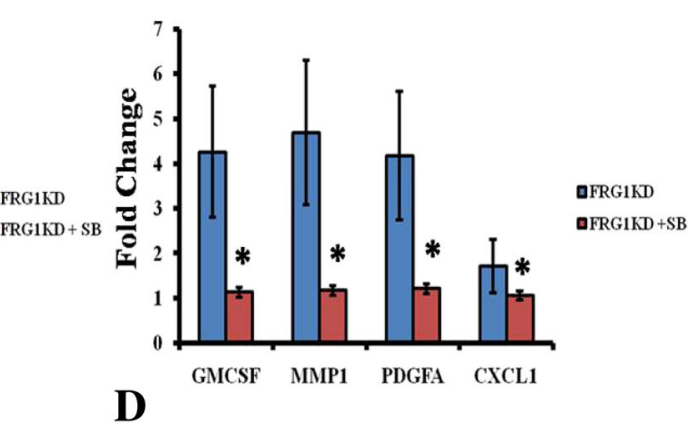

Fig. 8 p38 inhibition in FRG1 knockdown prostate cancer cells affects expression of various molecules: a. Representative Western blot panel showing reduction of phosphorylated p38 levels in the first lane after treatment with $0.5 \mu \mathrm{M}$ SB203580 in DU145 FRG1KD cells (Si). Phosphorylated p38 levels were higher in second lane with 0.1 MM SB203580 and in third lane with untreated FRG1KD cells (Si). We could also observe lower p38 phosphorylation levels in DU145 pLKO.1sc (Sc) cells (lane 4) compared to FRG1KD (Si) (lane 3). Third row representing FRG1 panel shows knockdown of FRG1 in FRG1KD (Si) cells compared to pLKO.1 Sc (Sc) cells. GAPDH levels were detected as loading control. b. Representative western blot panel showing reduction of phosphorylated p38 levels in the first lane after treatment with $0.5 \mu \mathrm{M}$ SB203580 in PC3 FRG1KD cells (Si). Phosphorylation levels were higher in second lane with $0.1 \mu \mathrm{M}$ SB203580 and in third lane with untreated FRG1KD cells (Si). We can also observe lower p38 phosphorylation levels in PC3 pLKO.1sC (Sc) cells compared to FRG1KD (Si). Third row representing FRG1 panel shows knockdown of FRG1 in FRG1KD (Si) cells compared to pLKO.1 sc (Sc) cells. GAPDH levels were detected as loading control. c. q-RT PCR based expression analysis of GM-CSF, MMP1 and PLGF in DU145 FRG1KD cells after $8 \mathrm{~h}$ of treatment with $0.5 \mu \mathrm{M}$ SB203580 (p38 inhibitor). Fold change in FRG1KD and FRG1KD + SB (p38 inhibitor) groups was derived in comparison with DU145 pLKO.1sc. After $8 \mathrm{~h}$ of treatment significant reduction in expression was observed in GM-CSF (FRG1KD, FC $=1.94$ vs. FRG1KD + SB, FC $=1.25$ ) and PLGF (FRG1 KD, FC $=2.59$ vs. $F R G 1 K D+S B, F C=1.13$ ) expression, no significant reduction was observed in case of MMP1 (FRG1KD, FC $=1.78$ to FRG1KD + SB, FC $=1.49$ ). $\mathbf{d}$. q-RT PCR based expression analysis of GM-CSF, MMP1, PDGFA and CXCL1 in PC3 FRG1KD cells after $8 \mathrm{~h}$ of treatment with $0.5 \mu \mathrm{M}$ SB203580 (p38 inhibitor). Fold change in FRG1KD and FRG1KD + SB groups was derived in comparison with PC3 pLKO.1sC. After $8 \mathrm{~h}$ of treatment significant reduction in GM-CSF (FRG1KD, $F C=4.26$ vs. FRG1KD + SB, FC= 1.12), MMP1 (FRG1KD, FC=4.69 vs. FRG1KD + SB, FC=1.17), PDGFA (FRG1KD, FC=4.17 vs. FRG1KD + SB, FC=1.21) and CXCL1 (FRG1KD, FC = 1.71 vs. FRG1KD + SB, FC= 1.05) expression was observed. In panel $C$ and $D$, t-test (2 tailed, for unpaired samples) was used for comparison of fold change values between experimental and control group. Each experimental group had three replicates. \# represents $p$ value $>0.05$, * represents $p$ value $<0.05$ " FC represents fold change

cell lines [34, 35]. But according to our finding MMP1 expression varies with cell type, suggesting that MMP1 levels might be regulated by FRG1 independent of p38 MAPK activity. PDGFA signaling is known to activate p38 MAPK in porcine aortic endothelial cells, leading to enhanced cellular migration [31]. Prior reports suggest that PC3 cells but not DU145, is positive for PDGFA receptor [36] which can be associated with activated p38 MAPK via enhanced PDGFA expression. Our findings show that p38 activation doesn't affect PDGFA levels but inhibition of p38 MAPK showed reduced expression of PDGFA. Similar to PDGF signaling, PLGF also activates p38 MAPK and, is known to enhance cellular migration in leukemia [37]. PLGF binds to Flt 1 receptor and exert activation of p38 MAPK in DU145 cells [38]. We have also first time reported effect on PLGF expression directly under the influence of p38 activation.

Overall, the effect exerted by FRG1 on prostate cancer cell properties and expression of various cytokines is mediated via p38 MAPK activity (Fig. 9). However, there is an impending question, regarding the mechanism of p38 activation during FRG1 knockdown. With no prior reports of association of FRG1 with above-mentioned molecules, which regulate tumor progression, further mechanistic studies are required to establish how FRG1 


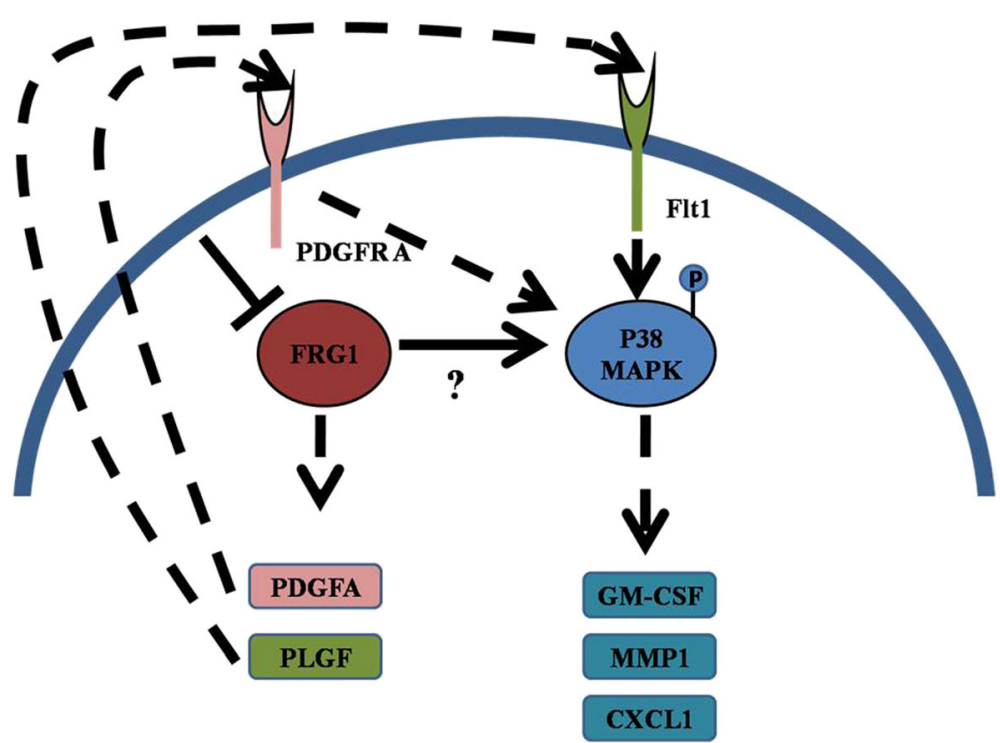

Fig. 9 Representation model for possible molecular interaction during FRG1 knockdown in prostate cancer cells

activates p38 MAPK, eventually leading to expression of certain cytokines and MMPs.

\section{Conclusion}

FRG1 expression levels are reduced in prostate tumor tissue and its expression affects the cell migratory and invasiveness properties of AR negative prostate cancer cell lines. FRG1 may exert its effect on tumorigenic properties through specific cytokines and MMPs via p38 MAPK activation. However, a better understanding is required to know on how FRG1 regulates these molecules.

\section{Additional files}

Additional file 1: Table S1. Genes with list of primers for which expression was determined in DU145 and PC3 cells with altered FRG1 expression. (PDF $37 \mathrm{~kb}$ )

Additional file 2: Table S2. Prostate cancer cohort used for $\mathrm{IHC}$ analysis of FRG1 expression. (PDF $118 \mathrm{~kb}$ )

Additional file 3: Correlation analysis of tumor IRS for FRG1, with Gleason score and MVD count. (PDF $96 \mathrm{~kb}$ )

Additional file 4: q-RT PCR based analysis of gene expression in DU145 cells and PC3 cells, with ectopic expression of FRG1. (PDF 104 kb)

\section{Abbreviations}

BMP4: Bone Morphogenetic Protein 4; CXCL1: Chemokine (C-X-C motif) ligand 1; dab2: Disabled 2; FRG1: FSHD Region Gene 1;

FSHD: Facioscapulohumeral Muscular Dystrophy; GM-CSF: Granulocyte Macrophage colony stimulating factor; HRP: Horse Radish Peroxidase; mDEC6: Murine Dental Epithelial Cell 6; MMP: Matrix metalloproteinase; MVD: Micro Vessel Density; NCCS: National Centre for Cell Science; PDGFA: Platelet Derived Growth Factor A; PDGFRa: Platelet Derived Growth Factor Receptor a; PLGF: Placental Growth Factor

\section{Acknowledgements}

The authors thank Mr. Dinesh Kumar Behera for his support in Immunohistochemistry.

\section{Funding}

This work was supported by DBT Grant BT/PR-14705/BRB/10/898/2010 DATED 30.09.2011, Ministry of science and Technology Govt. of India, to Dr. Manjusha Dixit. Fellowship was provided to Ankit Tiwari, Md. Khurshidul Hassan and Bratati Mukherjee, by Department of Atomic Energy, Govt. of India. Funding agency has no role in the design of the study and, collection, analysis and interpretation of data and, in writing the manuscript.

Availability of data and materials

The datasets used and/or analyzed during the current study are available from the corresponding author on reasonable request.

\section{Authors' contributions}

Experiments Designed: MD and AT. Experiments Performed: AT, BM. Data Analysis: AT, BM, MKH, NP and MD. Facility and Reagents: MD and AMJ. Manuscript Preparation: AT and MD. All the authors have reviewed and approved the final manuscript.

\section{Ethics approval and consent to participate}

The study was approved (Bioethics Reference \# MD-1) by Institutional Ethics Committee, National Institute of Science Education and Research (NISER), Bhubaneswar, India. All procedures performed were in accordance with the ethical standards of the institutional research committee and with the 1964 declaration of Helsinki and its later amendments or comparable ethical standards. The need for informed consent was waived by Institutional Ethics Committee, National Institute of Science Education and Research (NISER), Bhubaneswar, India, based on waiver of consent policy (page 23) of Ethical Guidelines for Biomedical Research on Human Participants, ICMR, 2006 (https://icmr.nic.in/sites/default/files/guidelines/ethical_guidelines_0.pdf). Cell lines used in this study, did not require ethical approval.

Consent for publication

Not applicable.

\section{Competing interests}

The authors declare that they have no competing interests.

\section{Publisher's Note}

Springer Nature remains neutral with regard to jurisdictional claims in published maps and institutional affiliations. 


\section{Author details}

${ }^{1}$ School of Biological Sciences, National Institute of Science Education and Research Bhubaneswar, HBNI, PO: Bhimpur-Padanpur, Via: Jatni, Odisha 752050, India. ${ }^{2}$ SRL Diagnostics Ltd, Plot 2084, Hall Plot 339/4820, Goutam Nagar Unit no. 28, Bhubaneswar, Odisha 751014, India.

Received: 2 August 2017 Accepted: 25 March 2019

Published online: 11 April 2019

\section{References}

1. Siegel RL, Miller KD, Jemal A. Cancer statistics 2015. CA Cancer J Clin. 2015; 65:5-29.

2. Ferlay J, Steliarova-Foucher E, Lortet-Tieulent J, Rosso S, Coebergh JWW, Comber H, Forman D, Bray F. Cancer incidence and mortality patterns in Europe: estimates for 40 countries in 2012. Eur J Cancer. 2013;49:1374-403.

3. Shtivelman E, Beer TM, Evans CP. Molecular pathways and targets in prostate cancer. Oncotarget. 2014;5:7217-59.

4. Attard G, Parker C, Eeles RA, Schröder F, Tomlins SA, Tannock I, Drake CG, Bono JSD. Prostate cancer. Lancet. 2016:387:70-82.

5. Grewal PK, Todd LC, Van Der Maarel S, Frants RR, Hewitt JE. FRG1, a gene in the FSH muscular dystrophy region on human chromosome $4 \mathrm{q} 35$, is highly conserved in vertebrates and invertebrates. Gene. 1998:216:13-9.

6. Wuebbles RD, Hanel ML, Jones PL. FSHD region gene 1 (FRG1) is crucial for angiogenesis linking FRG1 to facioscapulohumeral muscular dystrophyassociated vasculopathy. Dis Model Mech. 2009;2:267-74.

7. Adams JC. Roles of fascin in cell adhesion and motility. Curr Opin Cell Bio. 2004;16:590-6.

8. Hasegawa K, Wada H, Nagata K, Fujiwara H, Wada N, Someya H, Mikami Y, Sakai H, Kiyoshima T. Facioscapulohumeral muscular dystrophy (FSHD) region gene 1 (FRG1) expression and possible function in mouse tooth germ development. J Mol Histol. 2016;47:375-87.

9. Tiwari A, Pattnaik N, Mohanty Jaiswal A, Dixit M. Increased FSHD region gene1 expression reduces in vitro cell migration, invasion, and angiogenesis, ex vivo supported by reduced expression in tumors. Biosci Rep. 2017. https://doi.org/10.1042/BSR20171062.

10. Tate JG, Bamford S, Jubb HC, Sondka Z, Beare DM, Bindal N, Boutselakis H, Cole CG, Creatore C, Dawson E, et al. COSMIC: the catalogue of somatic mutations in Cancer. Nucleic Acids Res. 2019;47(D1):D941-7.

11. Gao J, Aksoy BA, Dogrusoz U, Dresdner G, Gross B, Sumer SO, Sun Y,

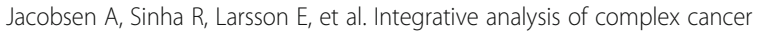
genomics and clinical profiles using the cBioPortal. Sci Signal. 2013;6:pl1.

12. Cerami E, Gao J, Dogrusoz U, Gross BE, Sumer SO, Aksoy BA, Jacobsen A Byrne CJ, Heuer ML, Larsson E, et al. The cBio cancer genomics portal: an open platform for exploring multidimensional cancer genomics data. Cancer Discov. 2012;2:401-4.

13. Mehrad M, LaFramboise WA, Lyons MA, Trejo Bittar HE, Yousem SA. Wholeexome sequencing identifies unique mutations and copy number losses in calcifying fibrous tumor of the pleura: report of 3 cases and review of the literature. Hum Pathol. 2018;78:36-43.

14. Erinjeri NJ, Nicolson NG, Deyholos C, Korah R, Carling T. Whole-exome sequencing identifies two discrete Druggable signaling pathways in follicular thyroid Cancer. J Am Coll Surg. 2018;226:950-9.

15. Fedchenko N, Reifenrath J. Different approaches for interpretation and reporting of immunohistochemistry analysis results in the bone tissue - a review. Diagn Pathol. 2014;9:221.

16. Weidner N, Folkman J, Pozza F, Bevilacqua P, Allred EN, Moore DH, Meli S, Gasparini G. Tumor angiogenesis: a new significant and independent prognostic indicator in early-stage breast carcinoma. J Natl Cancer Inst. 1992;84:1875-87.

17. Gabellini D, D'Antona G, Moggio M, Prelle A, Zecca C, Adami R, Angeletti B, Ciscato P, Pellegrino MA, Bottinelli R, et al. Facioscapulohumeral muscular dystrophy in mice overexpressing FRG1. Nature. 2006;439:973-7.

18. Hanel ML, Wuebbles RD, Jones PL. Muscular dystrophy candidate gene FRG1 is critical for muscle development. Dev Dyn. 2009;238:1502-12.

19. Hanel ML, Sun CYJ, Jones TI, Long SW, Zanotti S, Milner D, Jones PL. Facioscapulohumeral muscular dystrophy (FSHD) region gene 1 (FRG1) is a dynamic nuclear and sarcomeric protein. Differentiation. 2011;81:107-18.

20. Sun CYJ, Van Koningsbruggen S, Long SW, Straasheijm K, Klooster R, Jones TI, Bellini M, Levesque L, Brieher WM. Van Der Maarel SrM et al. Facioscapulohumeral muscular dystrophy region gene 1 is a dynamic RNAassociated and actin-bundling protein. J Mol Bio. 2011;411:397-416.
21. Osborne RJ, Welle S, Venance SL, Thornton CA, Tawil R. Expression profile of FSHD supports a link between retinal vasculopathy and muscular dystrophy. Neurology. 2007;68:569-77.

22. Patsialou A, Wang Y, Lin J, Whitney K, Goswami S, Kenny PA, Condeelis JS. Selective gene-expression profiling of migratory tumor cells in vivo predicts clinical outcome in breast cancer patients. Breast Cancer Res. 2012;14:1-19.

23. Chen SC, Frett E, Marx J, Bosnakovski D, Reed X, Kyba M, Kennedy BK. Decreased proliferation kinetics of mouse myoblasts overexpressing FRG1. PLoS One. 2011;6:e19780.

24. Liu AY. Differential expression of cell surface molecules in prostate cancer cells. Cancer Res. 2000;60:3429-34.

25. Ren T, Piperdi S, Koirala P, Park A, Zhang W, Ivenitsky D, Zhang Y, Villanueva-Siles E, Hawkins DS, Roth M, et al. CD49b inhibits osteogenic differentiation and plays an important role in osteosarcoma progression. Oncotarget. 2017:8:87848-59.

26. Vassilopoulos A, Chisholm C, Lahusen T, Zheng H, Deng CX. A critical role of CD29 and CD49f in mediating metastasis for cancer-initiating cells isolated from a Brca1-associated mouse model of breast cancer. Oncogene. 2014;33: 5477-82.

27. Dho SH, Lim JC, Kim LK. Beyond the role of CD55 as a complement component. Immune Netw. 2018;18:e11.

28. Koul HK, Pal M, Koul S. Role of p38 MAP kinase signal transduction in solid tumors. Genes Cancer. 2013:4:342-59.

29. Park JI, Lee MG, Cho K, Park BJ, Chae KS, Byun DS, Ryu BK, Park YK, Chi SG. Transforming growth factor-beta1 activates interleukin-6 expression in prostate cancer cells through the synergistic collaboration of the Smad2, p38-NFkappaB, JNK, and Ras signaling pathways. Oncogene. 2003;22:4314-32.

30. Savarese DM, Valinski H, Quesenberry P, Savarese T. Expression and function of colony-stimulating factors and their receptors in human prostate carcinoma cell lines. Prostate. 1998;34:80-91.

31. Matsumoto T, Yokote K, Tamura K, Takemoto M, Ueno H, Saito Y, Mori S Platelet-derived growth factor activates p38 mitogen-activated protein kinase through a Ras-dependent pathway that is important for actin reorganization and cell migration. J Biol Chem. 1999;274:13954-60.

32. Miyake M, Lawton A, Goodison S, Urquidi V, Rosser CJ. Chemokine (C-X-C motif) ligand 1 (CXCL1) protein expression is increased in high-grade prostate cancer. Pathol Res Pract. 2014;210:74-8.

33. Kuo PL, Shen KH, Hung SH, Hsu YL. CXCL1/GROalpha increases cell migration and invasion of prostate cancer by decreasing fibulin-1 expression through NF-kappaB/HDAC1 epigenetic regulation. Carcinogenesis. 2012:33:2477-87.

34. Johansson N, Ala-aho R, Uitto V, Grenman R, Fusenig NE, Lopez-Otin C, Kahari VM. Expression of collagenase-3 (MMP-13) and collagenase-1 (MMP1) by transformed keratinocytes is dependent on the activity of p38 mitogen-activated protein kinase. J Cell Sci. 2000;113:227-35.

35. Rappsilber J, Ryder U, Lamond Al, Mann M. Large-scale proteomic analysis of the human spliceosome. Genome Res. 2002;12:1231-45.

36. Liu $Q$, Jernigan $D$, Zhang $Y$, Fatatis A. Implication of platelet-derived growth factor receptor alpha in prostate cancer skeletal metastasis. Chin J Cancer. 2011;30:612-9.

37. Casalou C, Fragoso R, Nunes JFM, Dias S. VEGF/PLGF induces leukemia cell migration via P38/ERK1/2 kinase pathway, resulting in rho GTPases activation and caveolae formation. Leukemia. 2007;21:1590-4.

38. Ferrer FA, Miller LJ, Lindquist R, Kowalczyk P, Laudone VP, Albertsen PC, Kreutzer DL. Expression of vascular endothelial growth factor receptors in human prostate cancer. Urology. 1999;54:567-72.

\section{Ready to submit your research? Choose BMC and benefit from:}

- fast, convenient online submission

- thorough peer review by experienced researchers in your field

- rapid publication on acceptance

- support for research data, including large and complex data types

- gold Open Access which fosters wider collaboration and increased citations

- maximum visibility for your research: over $100 \mathrm{M}$ website views per year

At $\mathrm{BMC}$, research is always in progress.

Learn more biomedcentral.com/submissions 